\title{
Growth pattern and growth dependent mortality of larval and pelagic juvenile North Sea cod Gadus morhua
}

\author{
Rune Nielsen, Peter Munk* \\ Danish Institute for Fisheries Research, Charlottenlund Castle, 2920 Charlottenlund, Denmark
}

\begin{abstract}
We investigated growth patterns and evidence of growth dependent survival for a population of Atlantic cod Gadus morhua using analysis of their otolith microstructure. Central concentrations of a population of cod larvae and juveniles in the north-eastern North Sea were sampled twice (in April and May 2001), and larval/juvenile growth history from each of the sampling sequences was outlined. Growth rate was estimated by fitting a Laird-Gompertz equation to lengthsat-age, and we found the mean specific growth rate in length at age $20 \mathrm{~d}$ was $3.2 \% \mathrm{~d}^{-1}$, declining to $1.9 \% \mathrm{~d}^{-1}$ at an age of $90 \mathrm{~d}$. Otolith radius and larval standard length were highly correlated, and otolith growth was used as a measure of larval somatic growth. The larvae were divided into 3 groups dependent on their hatch-date, and for each hatch group, the same period of past growth was compared between fish sampled in April and May. A 2-way repeated-measurement ANOVA revealed a significant higher past growth of fish sampled in May in 2 of the 3 hatch-groups, implying a higher mortality of the slow growing larvae. Additionally, otolith size at age differed significantly between the April and May sampling of the oldest larvae. Using the obtained information we illustrate the consequences of being larger at age by nonparametric spline functions. These show up to 10 -fold differences in the relative survival probabilities between cod of smallest or largest size at age, suggesting that mortality can be strongly dependent on growth.
\end{abstract}

KEY WORDS: Gadus morhua $\cdot$ Otolith microstructure $\cdot$ Size-dependent mortality · Growth rate · Cod larvae

Resale or republication not permitted without written consent of the publisher

\section{INTRODUCTION}

Marine fish experience high mortality during their early life, and the survival variability in larval and juvenile stages is decisive for recruitment size in most fish stocks (Houde 1987, Cushing 1990, Leggett \& Deblois 1994). The major causes of mortality during larval life are starvation and/or predation, both of which are closely related to larval growth and size (Hunter 1972, Bailey \& Houde 1989). Larval escape ability increases with size, which lessens the predation risk during ontogeny, but being a larger size also increases the visibility of the larva (Williams et al. 1996, Chick \& Van Den Avyle 2000). Laboratory investigations have indicated that large individuals are less likely to suffer from starvation, while feeding ability, swimming speed, capture rate and perceptive distance are improved during ontogeny (Hunter 1972). However, this possible size advantage might be reduced when the influence of turbulence on feeding ability is taken into account (Legget \& Deblois 1994, Dower et al. 1998). It has been argued that a high growth rate reduces the duration of each stage in larval development, thereby lowering the cumulated mortality in the early stages, or promoting the larva's chance of outgrowing the reach of potential predators (Anderson 1988, Pepin 1991).

Positive selection for large or fast growing individuals has been much debated in the literature (Anderson 1988, Pepin 1991, Rice et al. 1993, Leggett \& Deblois 
1994, Cowan et al. 1996, 1997, Paradis et al. 1999). High predation pressure on small individuals has often been suggested as the decisive factor for an occurrence of selection for large or fast growing fish larvae (Bailey \& Houde 1989, Munk 2002). This 'size advantage' was questioned by Litvak \& Leggett (1992) and Pepin et al. (1992), who found higher predation rates on large individuals of larval capelin Mallotus villosus. They predicted that large individuals would be disadvantaged, due to a higher swimming speed which may lead to increased predator encounter. Paradis et al. (1999) argued that if both encounter and susceptibility to predation is a function of larval size, these factors will counteract each other, and as a result, size dependent differences in mortality will be difficult to detect in the field.

However, predation is not the only factor that has the potential to induce size dependent mortality; size dependent differences, for example, in foraging capability can lead to differential starvation of larvae when food is limited. Folkvord et al. (1997) found past growth differences in otoliths between larvae sampled periodically over the first month in a group of herring Clupea harengus, bred and reared in a mesocosm at low food abundance. Their results showed that larvae that survived until the termination of the experiment had on average experienced a higher historical growth than larvae sampled at an earlier time during the experiment. This suggests that slow growing individuals have a lower chance of survival, even in the absence of predators, and implies that part of the size dependent mortality can be caused by starvation solely, probably due to a low forage capability of small larvae (Hunter 1972, Pitchford \& Brindley 2001). The findings that increased size dependent mortality in larvae occur as a consequence of starvation (Folkvord et al. 1997) or as a consequence of predation (Rice et al. 1993) suggest that size selection on fish larvae is a phenomenon introduced during periods of high mortality under suboptimal conditions.

The appearance of growth dependent mortality can be tested by comparing previous growth rates of individuals from the same group of fish sampled at different times (West \& Larkin 1987). Comparisons between previous growth histories are possible by examining larvae otolith microstructure. Otolith formation in many fish larvae has been reported to occur on a circadian basis (Pannella 1971, Geffen 1995, Campana 2001), and the deposition rate of new material on the otolith is often correlated to the somatic growth of the fish larvae (Campana 1996, Meekan \& Fortier 1996, Suthers 1996, Otterleie et al. 2002). In such cases, the widths of the daily otolith increments can be used to reconstruct the somatic growth history of a fish (Campana 1990). Thus, the growth histories of larvae in a population sampled at a given time can be compared to growth histories in the fraction of the population that survived until a later sampling sequence. Such a comparison could indicate whether high growth rates are an advantage for survival. Growth dependent mortality will be reflected as differences in growth trajectories between fish sampled at the 2 sampling sequences (West \& Larkin 1987, Hovenkamp 1992, Meekan \& Fortier 1996, Sirois Dodson 2000). Given the problems associated with back-calculation, caused by individual differences in otolith-length scales (Francis 1990) and the possible decoupling of otolith and somatic growth (Mosegaard et al. 1988), several authors have suggested that the test for selection should be based exclusively on otolith size and growth, instead of using back-calculated larval length (Anderson 1995, Hare \& Cowen 1995, Folkvord et al. 1997).

Size dependent mortality of larvae from Atlantic cod Gadus morhua has been reported from the westerly areas of their distribution (Georges Bank, Campana 1996, and the Scotian shelf, Meekan \& Fortier 1996). The present study emphasises the growth history of a population of cod larvae and juveniles from the easterly areas of their distribution, in the North Sea, and investigates potential linkages between growth and mortality for this population. The cod recruitment processes in the North Sea were an element of an international research programme (LIFECO-LInking hydrographic Frontal activity to ECOsystem activity) carried out in the eastern part of the North Sea during 2001. This research programme investigates potential linkages between hydrographical frontal activity and the ecosystem dynamics at all trophic levels.

During the LIFECO programme a series of surveys were carried out. Two of the surveys enclosed a concentration of cod larvae/pelagic juveniles and afforded the material for the present analysis. Our primary goals were: (1) to describe growth rate and size at age for the population of cod larvae and pelagic juveniles, (2) to evince whether survival of cod larvae could be dependent on their sizes and/or growth rates, and (3) to estimate the possible effects of size and/or growth dependent mortality within the population.

\section{MATERIALS AND METHODS}

Sampling. Fish larvae and juveniles were sampled in the north-eastern North Sea during 2 cruises in 2001 on the RV 'Dana', the first from 18 April to 2 May (April cruise) and the second from 22 May to 4 June (May cruise). The sampling took place along transects, using 10 nautical mile station distances along the transects and 20 nautical mile separations between transects $\left(55.25^{\circ}\right.$ to $57.85^{\circ} \mathrm{N}, 3.25^{\circ}$ to $8.75^{\circ} \mathrm{E}$, Fig. 1$)$. A ring-net 

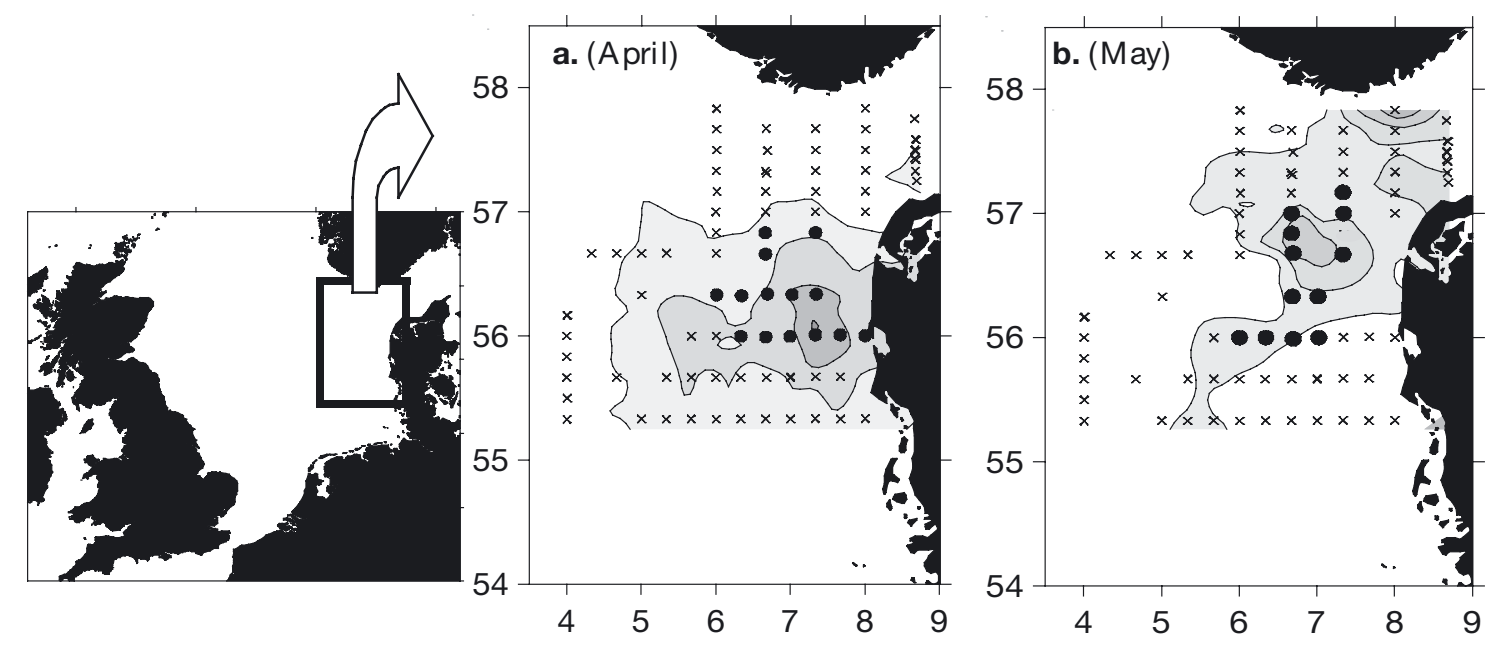

Fig. 1. Location of the study area in the north-eastern North Sea. (a) Sampling in April, (b) in May. $\times$ : indicates sampling positions, -: indicates positions from which larvae are taken for otolith examination. The shading of the contour plot illustrates relative abundance of cod larvae

with an opening of $3.14 \mathrm{~m}^{2}$ and a mesh size of $1000 \mu \mathrm{m}$ was used to sample fish larvae and pelagic juveniles. Sampling with the ring-net was carried out by an oblique tow from surface down to $5 \mathrm{~m}$ above the sea bottom. If the depth of a station was less than $20 \mathrm{~m}, 2$ oblique tows were made to increase the sample size. The ring-net was towed with a speed of approximately $1.5 \mathrm{~m} \mathrm{~s}^{-1}$ and duration of the hauls was between 8 and 25 min depending on depth. A flow meter placed in the opening of the ring-net recorded the flow of water in the net, and a depth sensor mounted on the net frame recorded haul profile. All sampled gadoid larvae and juveniles were immediately preserved in $96 \%$ ethanol, which was renewed after approximately $48 \mathrm{~h}$ in order to avoid acidification (Butler 1992). In the laboratory all larvae and pelagic juveniles of Atlantic cod Gadus morhua were sorted and enumerated. Larval or juvenile stages are collectively called larvae in the following sections. The standard length of all larvae caught in the selected area was measured under a dissection microscope to the lowest $0.5 \mathrm{~mm}$ and the larvae were grouped in $5 \mathrm{~mm}$ size classes. All larvae were soaked in freshwater for approximately $5 \mathrm{~min}$ before they were measured, no correction for shrinkage was applied.

Selection of larvae and analysis of otoliths. For our analysis of the growth pattern in the larval population, we aimed to select larvae representative of the covered larval distribution. For each survey, the central parts were identified from stations with peak abundances of larvae (Fig. 1). Across the central area we selected stations, each of which represented equal sized sub-areas within the larger area. (Fig. 1). From these stations we then sampled larvae in proportion to their abundance (in numbers $\mathrm{m}^{-2}$ ) within length groups. Sampling in the survey area on both cruises covered a time period of approximately $2 \mathrm{wk}$. In total, 105 and 107 larvae were selected to represent the population at the April and May surveys, respectively, and were used in the analysis of growth dependent mortality. An additional 43 larvae were analysed and added to the dataset for estimation of somatic growth rates. The otoliths were extracted under dissection microscope with fine needles and mounted in thermoplastic cement (Buehler®) on a glass slide. Lapillii were used as an alternative to the sagittal otolith, because of the more regular pattern of increment deposition in the larger specimens. Lapillii are known to form daily increments after hatching, and there is a good relationship between lapillus size and the length of cod larvae (Geffen 1995, Clemmesen \& Doan 1996, Meekan \& Fortier 1996, Suthers 1996). One lapillus from each fish was ground on both sides using lapping film (3M Imperial ${ }^{\mathrm{TM}}$ ) with 1 to $5 \mu \mathrm{m}$ grids. The otoliths were examined using a light microscope with a $63 \times$ magnification objective lens. The microscope was equipped with video camera and computer with Image-pro plus $\odot$ software. Hatch radius and daily increment width on each individual otolith was measured along the same axis, starting from the core to the edge of the otolith. The otoliths are bilaterally symmetric, and the axis of symmetry was chosen as the measuring axis (as in Suthers et al. 1989). Measurements were taken with $0.1 \mu \mathrm{m}$ precision.

Analysis of growth. The growth of larvae was estimated from length-at-age by a non-linear LairdGompertz equation, which has previously been found useful for description of the growth of fish larvae (Bolz \& Lough 1988, Munk 1993a). The variance was stabilised by transforming length data to its natural logarithm and was fitted to the following (Bolz \& Lough 1988) equation: 


$$
\ln (L)=\ln \left(L_{0}\right)+\beta[1-\exp (\alpha t)]
$$

where $L$ is the length in $\mathrm{mm}$, and $t$ is the age estimated by the number of increment on the otolith. $L_{0}$ (the length at hatching), $\beta$ and $\alpha$ are the model parameters, where $\alpha$ is the instantaneous rate of growth at the inflection point of the curve, and $\beta$ is a dimensionless parameter. When the model parameters are found, the length increase at age can be estimated by the derivation of Eq. (1):

$$
\mathrm{d} L / \mathrm{d} t=L_{0} \beta \alpha \exp \{\beta[1-\exp (-\alpha t)]-\alpha t\}
$$

The hatch date of the individual larva was determined by subtracting age, estimated by otolith analysis, from the date of catch (Campana \& Jones 1992). The hatch dates are used to group larvae in time, and to evaluate whether larvae sampled in April and May hatched during the same time period. A MannWhitney $U$ test and a Kolmogorov-Smirnov 2-sided test were used to compare frequency distributions of hatch dates of larvae from the 2 cruises.

In the analysis of growth dependent survival, larvae sampled on the cruise in May were assumed to represent the population sampled in April. The growth histories of cod populations from April and May were then tested against each other to assess growth dependent selection. Standard lengths of the larvae were plotted against otolith radius in order to validate the relations between fish and otolith sizes. In order to limit the influence of temporal variation in environmental conditions in the analysis, the larvae were divided in 3 subgroups depending on hatch date. The corresponding hatch groups from the 2 cruises were subsequently tested against each other for differences in otolith growth and size. To avoid statistical problems caused by missing values the data were truncated, and the maximum age tested in a group was therefore determined by the age of the youngest fish in the tested groups (Chambers \& Miller 1995). Differences between groups in otolith growth over time were analysed by a 2-way repeated measurement ANOVA (RM ANOVA). Data received from multiple measures per otolith cannot be assumed to be independent, and the RM ANOVA test accounts for the longitudinal nature of the data (Chambers \& Miller 1995). The longitudinal basis of the data will decrease the effect of a possible delay in otolith growth. Such a delay has been observed, and this might influence the interpretation of otolith increment width (Pepin et al. 2001). The measures of the otolith increment were averaged in $3 \mathrm{~d}$ intervals and logtransformed to reduce the variance. All RM ANOVA tests were performed in the software Statistical Analysis System ${ }^{\circledR}$. Difference between sizes of the hatch marks in April and May were tested by a $t$-test.
A $t$-test was performed on the otolith radius on the last age available in the truncated data in each of the 3 hatch groups (i.e. at the age of the youngest fish in the tested groups). Using this result, we investigated whether otolith growth led to significant differences in otolith size-at-age between fish sampled in April and May. The otolith size-at-age comparison was also used to investigate how sensitive our findings are to the interpretation of population centre in April and May. Hence, we divided the April and May samples into equally sized northern and southern subsets of data (separated at latitude 56.1 and $56.85^{\circ} \mathrm{N}$ for April and May, respectively), and in addition to the overall comparison we compared size-at-age information between these subsets of data. The relative survival related to otolith size-at-age was estimated by the use of the nonparametric smoothing spline introduced by Anderson (Anderson 1995). Given the high mortality of fish larvae, Anderson (1995) set the individual survival before selection to 0 and the individual survival of fishes sampled after selection to 1 , since they had survived. With these assumptions Anderson showed that in a 'before-after' comparison of a cohort, the relative survival $f$, explained by a quantitative trait $z$ (in this case the otolith size-at-age), can be described by the equation:

$$
f(z)=\frac{S_{2}}{S_{1}} \times \frac{h(z)}{1-h(z)}
$$

Where $S_{1}$ is the number of otoliths examined from the sample before selection (April), $S_{2}$ is the number of otoliths examined from the sample taken after selection (May) and $h(z)$ is explained by Eq. (4):

$$
h(z)=\frac{S_{2}(z)}{S_{2}(z)+S_{1}(z)}
$$

where $h(z)$ is determined by a nonparametric smoothing spline to Eq. (4) (Anderson 1995) and $f(z)$ (the relative survival) was calculated from Eq. (3).

\section{RESULTS}

In April the central parts of larval distribution were traced to the Horns reef area, while the central areas appeared a further 50 nautical miles north in May (Fig. 1). Abundance estimates in April varied between 0.13 and 2.94 individuals $\mathrm{m}^{-2}$ and between 0.01 and 0.39 individuals $\mathrm{m}^{-2}$ in May. The standard lengths of the larvae were between 6.3 and $36.5 \mathrm{~mm}$ in April and between 9.3 and $57.3 \mathrm{~mm}$ in May. Larval mean length was $13.9 \mathrm{~mm}$ in April, increasing to $28.9 \mathrm{~mm}$ in May. The overall growth rate of cod larvae was analysed using Eq. (1) and Eq. (2) on all size-at-age data (243 larvae) (Fig. 2). We estimated length at hatching to be 
$3.06 \mathrm{~mm}$ (preserved length) and a daily growth rate varying from $0.20 \mathrm{~mm} \mathrm{~d}^{-1}$ at age $20 \mathrm{~d}$ to $0.698 \mathrm{~mm} \mathrm{~d}^{-1}$ at age $90 \mathrm{~d}$ (Table 1). This corresponds to a decline in the mean specific growth in length from $3.2 \% \mathrm{~d}^{-1}$ at age $20 \mathrm{~d}$ to $1.9 \% \mathrm{~d}^{-1}$ at age $90 \mathrm{~d}$. The confidence limits illustrate the considerable difference in size at age between the largest and smallest members (at age) of the population (Table 1).

The cod larvae from the investigated area were between 22 and $115 \mathrm{~d}$ old. Hatch dates calculated for each individual larva were accumulated into groups of $10 \mathrm{~d}$, which reveal the frequency distribution illustrated in Fig. 3. We found that cod larvae caught on the cruise in April hatched during the period from February 4 to April 13 while larvae caught in May hatched during the period from February 1 to April 26. An analysis of the hatch dates showed that differences between mean estimated hatching time for the popula-

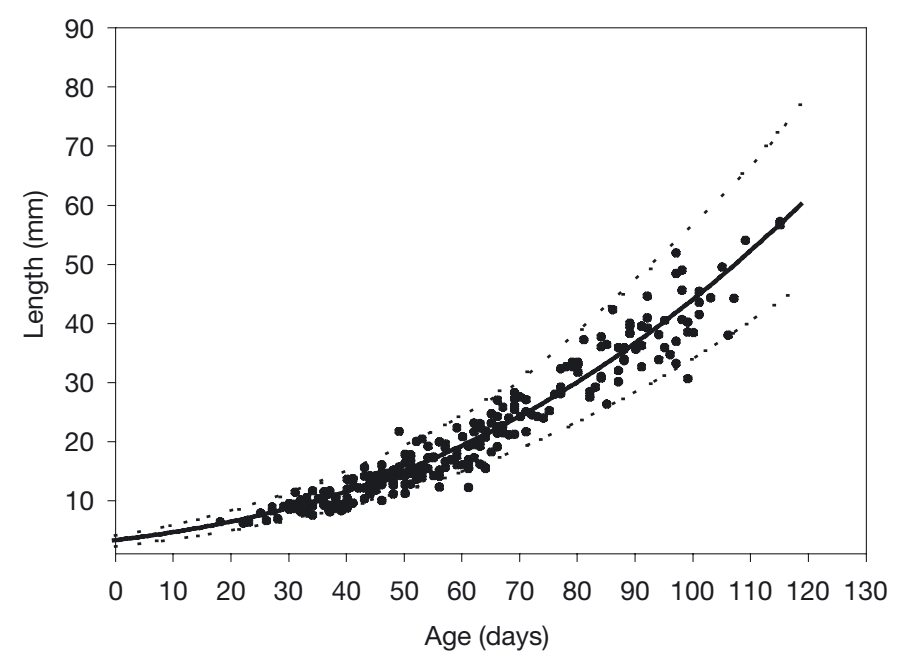

Fig. 2. Gadus morhua. Estimated length-at-age. Full line illustrates Laird-Gompertz Eq. (1) fit to data of length $(\mathrm{mm})$ at age (d). Dotted lines indicate the $95 \%$ confidence limits

Table 1. Gadus morhua. Mean length and growth at age, estimated by LairdGompertz equations, from ages 20 to $90 \mathrm{~d}$. CL: confidence limit

\begin{tabular}{|lccccc|}
\hline $\begin{array}{l}\text { Age } \\
(\mathrm{d})\end{array}$ & $\begin{array}{c}\text { Mean } \\
\text { length } \\
(\mathrm{mm})\end{array}$ & $\begin{array}{c}\text { Lower 95\% } \\
\text { CL } \\
(\mathrm{mm})\end{array}$ & $\begin{array}{c}\text { Upper 95\% } \\
\text { CL } \\
(\mathrm{mm})\end{array}$ & $\begin{array}{c}\text { Growth } \\
\text { rate } \\
\left(\mathrm{mm} \mathrm{d}^{-1}\right)\end{array}$ & $\begin{array}{c}\text { Specific growth } \\
\text { in length } \\
\left(\% \mathrm{~d}^{-1}\right)\end{array}$ \\
\hline 20 & 6.17 & 4.75 & 8.01 & 0.20 & 3.2 \\
30 & 8.43 & 6.52 & 10.91 & 0.25 & 3.0 \\
40 & 11.27 & 8.74 & 14.55 & 0.31 & 2.8 \\
50 & 14.76 & 11.46 & 19.01 & 0.38 & 2.6 \\
60 & 18.96 & 14.74 & 24.38 & 0.46 & 2.4 \\
70 & 23.91 & 18.60 & 30.73 & 0.54 & 2.2 \\
80 & 29.66 & 23.07 & 38.12 & 0.60 & 2.1 \\
90 & 36.23 & 28.16 & 46.59 & 0.70 & 1.9 \\
\hline
\end{tabular}

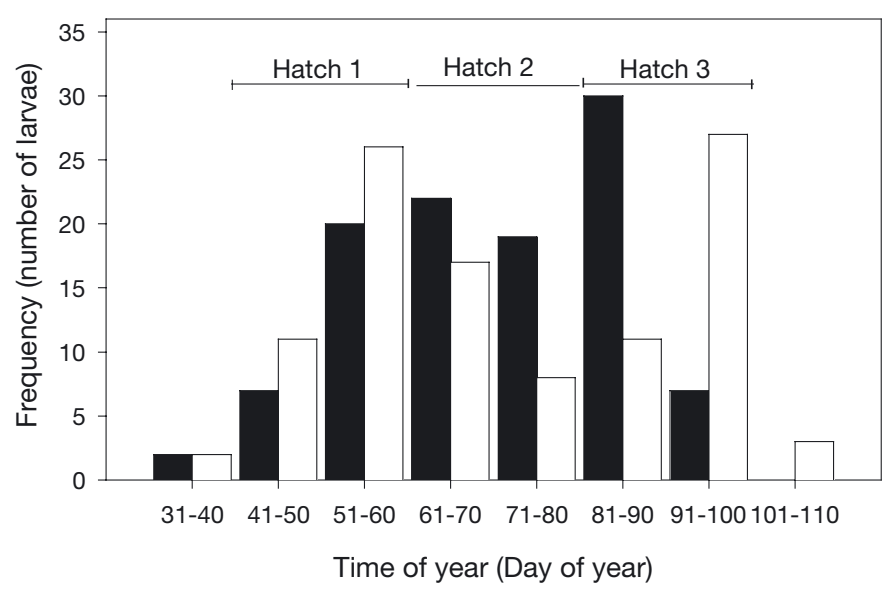

Fig. 3. Gadus morhua. Hatch date distributions of larvae from April (illustrated by black bars, $\mathrm{n}=107$ ), and May (illustrated by white bars, $n=105$ )

tion sampled in April and May were insignificant (Mann-Whitney $U$ test, $\mathrm{p}>0.05$ ); however the frequency distributions of hatch dates found for larvae sampled in April and May differed significantly (Kolmogorov-Smirnov 2-sample test, $\mathrm{p}<0.05$ ). Larvae that hatched after April 18 (start of the first cruise) were not included in this analysis.

Otolith radii were measured and plotted against the standard length of the larvae (Fig. 4). The relationships between otolith size and larval length were not significantly different $(p>0.05)$ between the April and May samplings, and data from the 2 cruises were combined. A high correlation indicated that size and growth of the otoliths were good descriptors of the somatic size and growth pattern of the cod larvae. The radius of hatch marks on lapillus was between 8 and $12 \mu \mathrm{m}$. No significant differences in hatch-mark size were found between fish sampled in April and May ( $t$-test $\mathrm{p}>0.05$, in all hatch groups). The mean daily growth of the otoliths along the axis of measurement increased from approximately $1 \mu \mathrm{m}$ at hatch to about $4 \mu \mathrm{m}$ at age $90 \mathrm{~d}$ (Fig. 5).

Larvae that hatched at different times, but were sampled on the same cruise were divided into 3 hatch groups of $20 \mathrm{~d}$ intervals from (1) Day of year 41 to $60,(2)$ Day of year 61 to 80 , and (3) Day of year 81 to 100 (Table 2 \& Fig. 3). Two larvae from May and 12 from April which hatched before day 41 or after Day 100 were not included in the statistical analysis. The mean growth in hatching groups illustrates the pattern in growth (Fig. 6). Larvae 


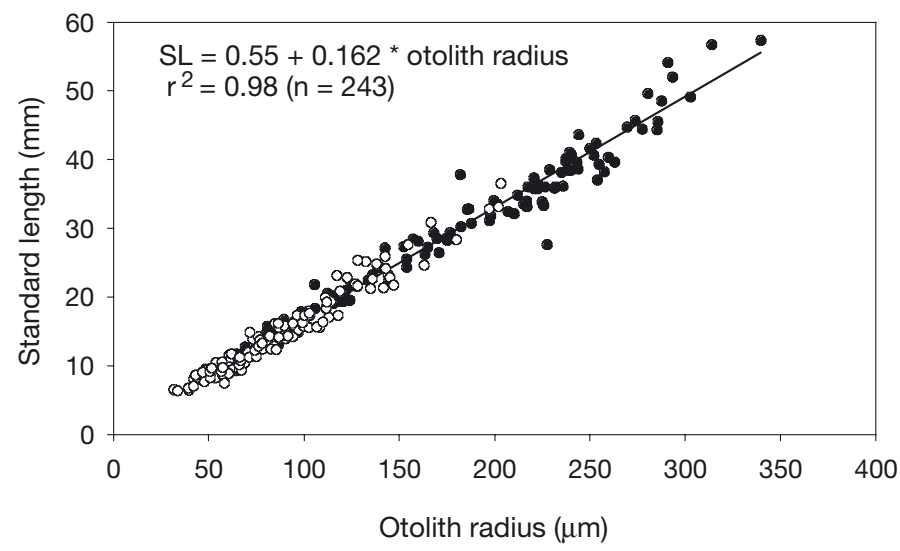

Fig. 4. Gadua morhua. Standard length versus radius of the lapillus. Fish caught in April are symbolised by open circles and fish from May by full circles

in Hatch groups 1 and 2 had on average higher growth rates in May than the larvae sampled in April (Fig. 6a,b), while the opposite was the case for Hatch group 3 (Fig. 6c). Statistical analysis (RM ANOVA) of the growth difference between April and May sampling revealed a significant difference for both Hatch groups 1 and 2, when the difference for Hatch group 3 was insignificant (Table 3).

Influence of sampling time on otolith size-at-age was tested for each of the 3 hatch groups. In addition, we investigated the influence of our choice of sampling area by a comparison of spatial subsets of the dataset for Hatch group 1. In each of the 3 hatch groups, we used the oldest age of the truncated data, i.e. age $52 \mathrm{~d}$ in Hatch group 1, $32 \mathrm{~d}$ in Hatch group 2 and $22 \mathrm{~d}$ in Hatch group 3 (Table 3, Fig. $7 \mathrm{a}-\mathrm{c})$. The otolith radius at age was found by adding the hatch radius and increment measures. Differences in otolith size at age between larvae sampled in April and May in Hatch groups 2 and 3 were insignificant $(t-$ test, p > 0.05, Table 3). For Hatch group 1 there was a significant difference in the radius of the otoliths ( $t$-test, $\mathrm{p}<0.05$, Table 3 ), the otolith sizes being larger in larvae sampled in May (Fig. 7a). Our pair-wise comparison of the 4 subsets of data for Hatch group 1 (a southerly, and a northerly for both April and May) showed that the otolith sizes were largest in May in all com-

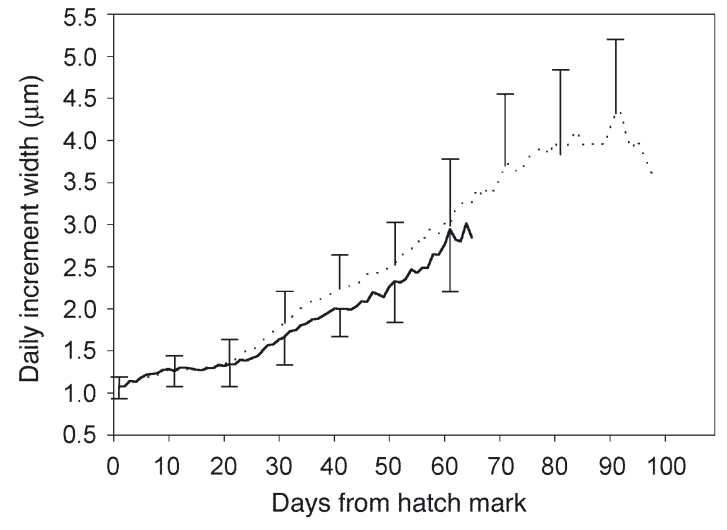

Fig. 5. Gadus morhua. Average daily growth of the lapillus from larvae and pelagic juvenile cod caught in April (solid line) and May (dotted line). The standard deviation of daily increment widths is shown for every tenth day; for April only the lower SD is shown, while the upper is shown for May

parisons. Of these the comparisons between the northerly area in April and both areas in May were significant $(t$-test, $\mathrm{p}<0.05)$.

The relative influence of otolith size on larval survival was analysed by Eq. (3) and Eq. (4) (Fig. 8). Conspicuous changes in the survival probability dependent on otolith size are apparent from this analysis. By definition, the mean survival $(f)$ is 1.0 at

Table 2. Gadus morhua. Larval number, age (d) and length ( $\mathrm{mm}$ ) in each of the 3 hatch groups from the 2 cruises

\begin{tabular}{|lccccr|}
\hline $\begin{array}{l}\text { Hatch } \\
\text { group }\end{array}$ & Cruise & $\begin{array}{c}\text { Hatch period } \\
\text { (Day of year) }\end{array}$ & $\begin{array}{c}\text { Number of } \\
\text { larvae }\end{array}$ & $\begin{array}{c}\text { Ages at } \\
\text { catch (d) }\end{array}$ & $\begin{array}{r}\text { Length at } \\
\text { catch (mm) }\end{array}$ \\
\hline 1 & April & $41-60$ & 27 & $52-79$ & $12.3-36.5$ \\
1 & May & $41-60$ & 37 & $87-106$ & $30.2-54.1$ \\
2 & April & $61-80$ & 41 & $32-59$ & $8.8-17.9$ \\
2 & May & $61-80$ & 25 & $69-94$ & $21.5-42.4$ \\
3 & April & $81-100$ & 36 & $22-40$ & $6.3-12.0$ \\
3 & May & $81-100$ & 30 & $47-66$ & $12.9-24.3$ \\
\hline
\end{tabular}

Table 3. Gadus morhua. Results of the statistical comparison of otolith hatchmark radius, otolith radius at age and development of increments width between the 2 cruises. * Significant $(p<0.05)$

\begin{tabular}{|c|c|c|c|}
\hline $\begin{array}{l}\text { Hatch date } \\
\text { (Day of year) }\end{array}$ & $\begin{array}{l}\text { Hatchmark } \\
\text { radius ( } t \text {-test) }\end{array}$ & $\begin{array}{c}\text { Otolith radius } \\
\text { at the end of the } \\
\text { growth period ( } t \text {-test) }\end{array}$ & $\begin{array}{l}\text { Width of } 3 \text { increments } \\
\text { intervals } \\
\text { (RM ANOVA) }\end{array}$ \\
\hline $\begin{array}{l}41-60 \\
\text { April versus May }\end{array}$ & $p=0.359$ & $\begin{array}{c}\mathrm{p}=0.025^{*} \\
\text { (at age } 52 \mathrm{~d} \text { ) }\end{array}$ & $\mathrm{p}=0.0033^{*}$ \\
\hline $\begin{array}{l}61-80 \\
\text { April versus May }\end{array}$ & $p=0.433$ & $\begin{array}{c}p=0.337 \\
\text { (at age } 32 \mathrm{~d} \text { ) }\end{array}$ & $\mathrm{p}=0.0039^{*}$ \\
\hline $\begin{array}{l}81-100 \\
\text { April versus May }\end{array}$ & $p=0.908$ & $\begin{array}{c}p=0.176 \\
\text { (at age } 22 \mathrm{~d} \text { ) }\end{array}$ & $\mathrm{p}=0.5400$ \\
\hline
\end{tabular}


the mean otolith size in the first sample. For Hatch group 1, which showed significant difference between samplings (Table 3 ) the analysis indicated that larvae with larger otoliths had relative chance of survival between 1 and 2, while fish with otoliths smaller than the mean had a relative chance of survival between 0.05 and 1 (Fig. 8a). For Hatch group 2 we also find an increasing relative survival at increasing otolith size (Fig 8b). In Hatch group 3 we find a decreasing relative survival at increasing otolith size (Fig 8c). Note, however, that the survival curves for Hatch groups 2 and 3 are based on insignificant differences in otolith size between cruises (Table 3 ).
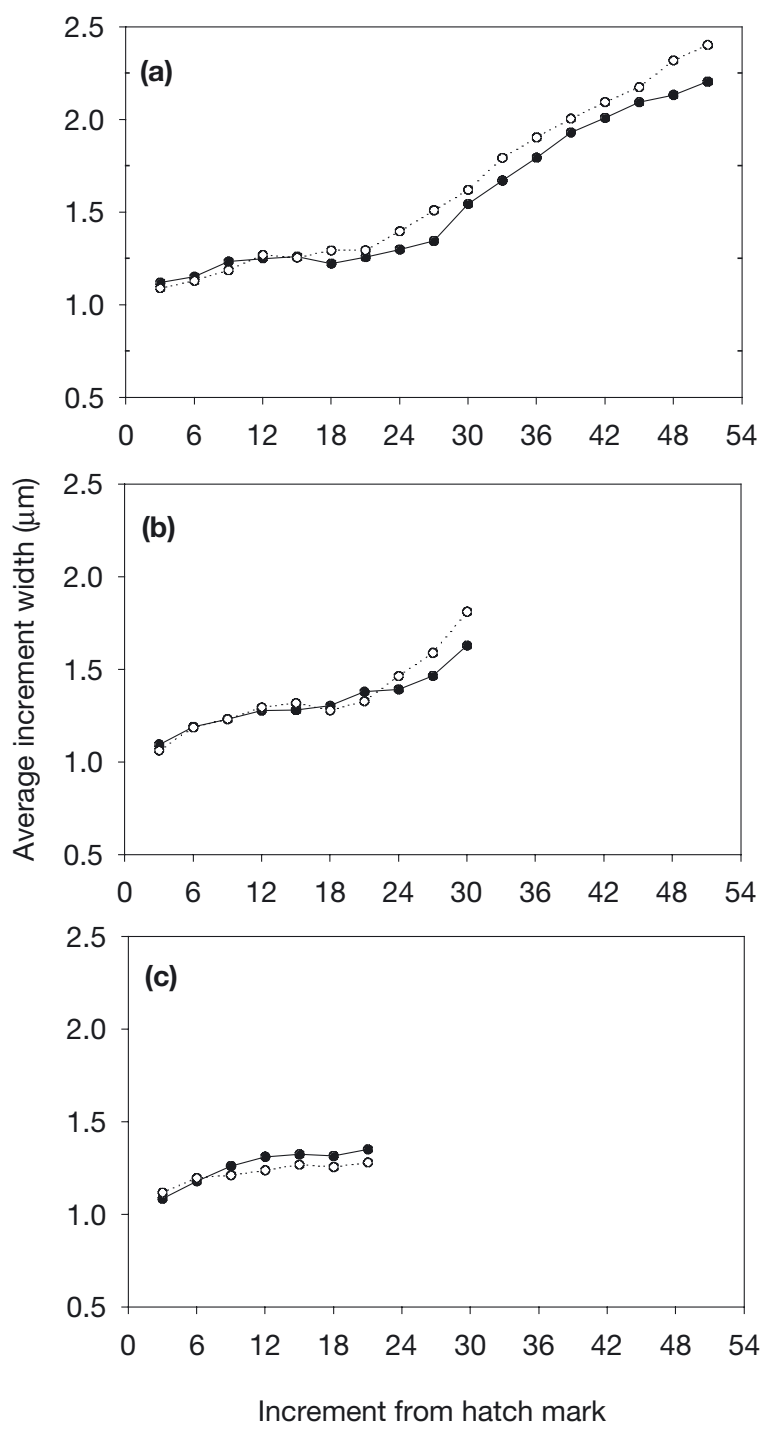

Fig. 6. Gadus morhua. Average width of the daily increment of the lapillus otolith. Solid lines and filled circles represent cod larvae caught in April, dotted lines and open circles represent cod larvae caught in May. (a) Hatch group 1, from Day of year 41 to 60; (b) Hatch group 2, from Day of year 61 to 80; (c) Hatch group 3, from Day of year 81 to100
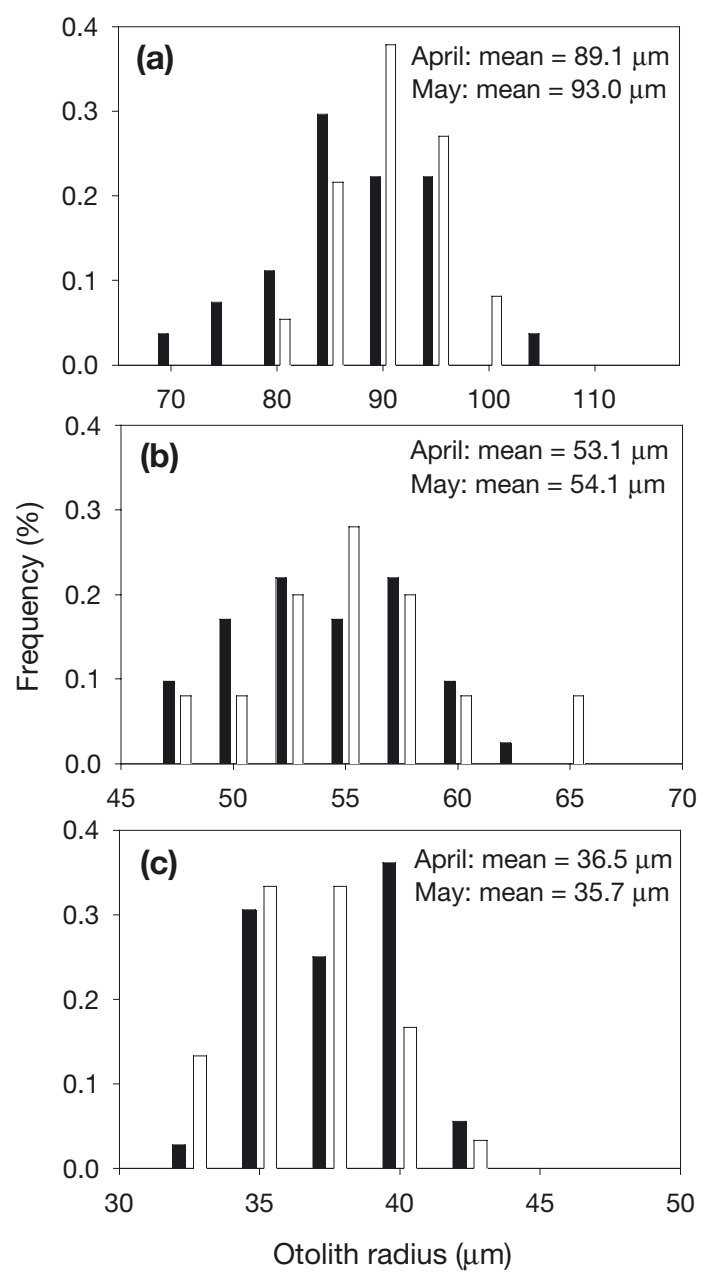

Fig. 7 Gadus morhua. Otolith size distributions for each hatch group with corresponding mean values. Black bars represent otoliths from larvae caught in April and white bars represent otoliths from larvae caught in May. (a) Larvae at age $52 \mathrm{~d}$, hatching from Day of year 41 to 60; (b) Larvae at age $32 \mathrm{~d}$ hatching from Day of year 61 to 80; (c) Larvae at age $22 \mathrm{~d}$ hatching from Day of year 81 to 100

\section{DISCUSSION}

The present study suggests growth dependent differences in the survival of North Sea cod larvae. In 2 of the 3 hatch groups a significantly higher otolith growth was found for the population surviving from April to May. Furthermore, the otolith sizes at a given age were significantly different for larvae in the Hatch group 1, where size at age was larger for larvae sampled in May compared with those sampled in April. This implies that the larger larvae had a better chance of survival. The calculation of the relative survival chance indicates that larvae with small otoliths have a chance of survival below 0.2 , which was considerably lower than the survival mean of 1.0. On the other hand, larvae with otoliths 

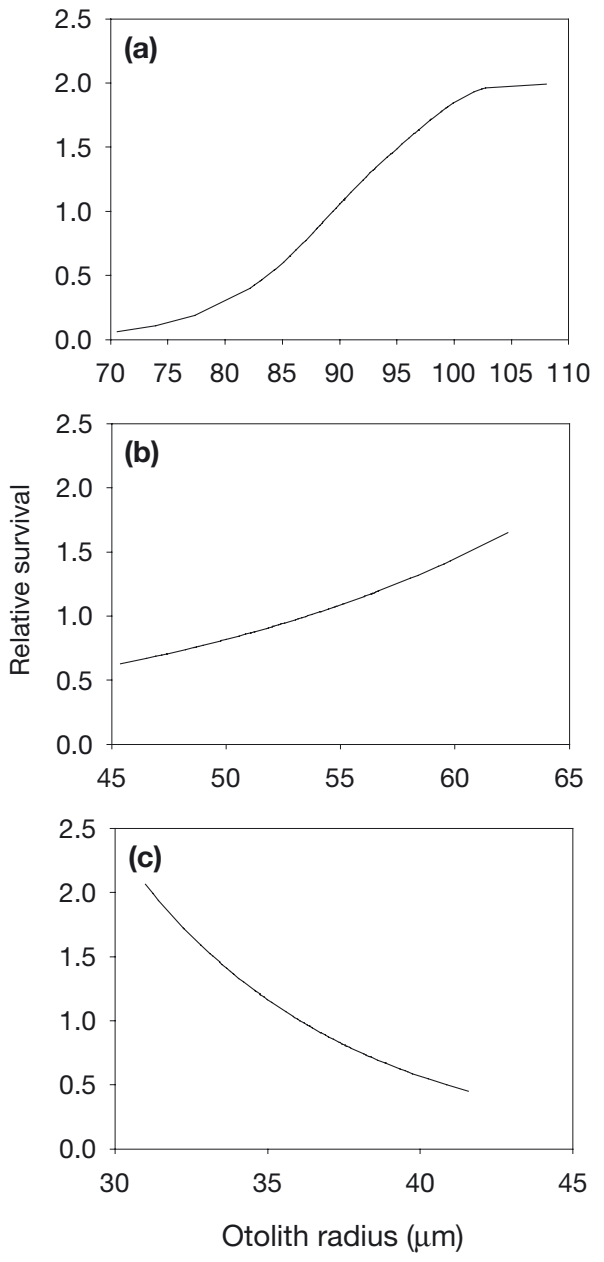

Fig. 8. Gadus morhua. Relative survival of cod as function of otolith size (radius). Estimated as described in text. (a) Larvae at age $52 \mathrm{~d}$, hatching from Day of year 41 to 60. Data used are significant, $\mathrm{p}<0.05$. (b) Larvae at age $32 \mathrm{~d}$ hatching from Day of year 61 to 80 . Data used are insignificant, $p>0.33$. (c) Larvae at age $22 \mathrm{~d}$ hatching from Day of year 81 to 100 . Data used are insignificant, $p>0.17$

larger than the mean had a relative chance of survival that was up to 2 times higher than the mean. The large differences in relative survival estimated for Hatch group 1 indicates that size at age can have a considerable influence on survival. The result suggests that size variation of the range found in this investigation can lead to more than a tenfold difference in survival between the smallest and the largest fish. The suggested magnitude of the growth/size influence are in accordance with the analysis by Houde (1987) and Luecke et al. (1990) who showed that small differences in growth and size during larval/juvenile stages could result in large differences in accumulated mortality. Hence, the present findings support the hypothesis that differences in mean growth rate within the range commonly observed will result in a large variation in survival.
Our estimates of cod growth rate are within the ranges that have previously been reported from field and laboratory studies (Bolz \& Lough 1988, Geffen 1995, Puvanendran \& Brown 1999). However, the presented mean growth rates might have been overestimated slightly while a size selection would bias the growth curve upwards (Heath \& Gallego 1997). Individual differences in growth rate of fish larvae are commonly observed (e.g. Suthers et al. 1989, Munk 1993a) and also our size at age estimates shows considerable differences between individuals (Fig. 2, Table 1). In their investigation of growth and survival of cod larvae from the Scotian Shelf Meekan \& Fortier Meekan \& Fortier (1996) concluded that selection for fast growing larvae was strongest under poor growth conditions. However our study, which was carried out on larvae growing faster than those on the Scotian shelf, also indicated growth dependence of survival.

A central assumption in our study is that the groups of larvae we compared are from the same population. A number of observations support this assumption. (1) We estimated the position of the central concentration of cod larvae in May to be approximately 50 nautical miles north of the central concentration in April. A northbound drift is in accordance with the prevalent north floating currents in the area, supported by models of the currents during the period (C. Schrum, University of Hamburg, pers. comm.). (2) The estimates of mean hatching time deviate by only 2 d between our samples from the 2 samplings. (3) The earliest growth history is the same for larvae sampled in April and May. This indicates that the larvae at earlier ages have experienced the same growth conditions, and so it is probable that the same population was sampled by the 2 sampling sequences. (4) Another factor that could influence our findings is the gear selectivity. The catch of larvae and juveniles can be affected if the net does not retain the smallest individuals, or if large individuals are capable of avoiding the net (Butler 1992). The smallest larvae might not be fully retained by the $1 \mathrm{~mm}$ coarse mesh of the net, while Munk (1993b) describes increasing gear avoidance by the largest juveniles. A possible bias due to selectivity by the gear could cause an underestimation of the smallest larvae in April and the largest larvae in May, which would explain the differences found the frequency distribution of hatch date. Hence, this bias would be conservative with respect to the indication of growth dependent mortality in the present analysis. Such a bias (i.e. the under representation of small individuals (slow growers) in April and of large individuals in May (fast growers)) would lead to an increase in estimates of growth rate of the April samplings and a decrease in estimates of growth rate of larvae from the May samplings. (5) We investigated the 
influence of spatial variation in growth by comparing subsets of data that had other spatial extension than the one used in our primary analysis. In all comparisons, the otolith size at age in the May samples was the largest, hence, the general interpretation of promoted growth by the survivors was not changed by this modification of sampling areas.

The applicability of historical growth analysis using otolith sizes has been widely discussed (Mosegaard et al. 1988, Francis 1990, Hare \& Cowen 1995, Miller et al. 1999, Otterleie et al. 2002). Mosegaard et al. (1988) found that the relationship between otolith size and length in arctic char Salvelinus alpinus depended on temperature, as the otolith and the somatic growth responded differently to changes in temperature. (Otterleie et al. 2002) showed that this was also true for cod larvae, but they also found that fast growing larvae had larger otoliths than slow growing individuals of the same age reared under the same temperature conditions. In studies of selectivity hatch time is important, as growth is dependent on food availability and temperature, which varies over time. In the present study grouping of larvae into hatch date groups was used in order to diminish the effect of variation in environmental conditions. Optimally a test for size selectivity should be conducted at daily intervals. In this investigation larvae of different ages are grouped in intervals of $20 \mathrm{~d}$. If survival is growth dependent, a consequence of this procedure could be an overestimation of growth, since larvae that are older than the tested age will bias the result, as they were able to survive for a period of time after the tested growth period. However, such bias of larval growth will make it more difficult to reject the null hypothesis of there being no difference between larvae sampled on the 2 cruises, hence, it is conservative with respect to our findings of growth and size differences.

Rice et al. (1993) and Cowan et al. (1996) showed that individual variations in growth would not lead to instantaneous changes in mortality, since growth differences should accumulate to marked size differences before differences in mortality occurs. Consequently differences in mortality should become more pronounced at increasing age since growth differences have accumulated. This might be the background of the differences among our hatch groups. We found the strongest support of growth selective mortality in the group with the oldest cod larvae, where both the historical growth and the size at age differ significantly between April and May samples. Differences in mean growth rate of the population are not detectable before a given period after the hatch ( 2 to 3 weeks). The difficulties in detecting differences in the first period might be due to the small variation in size compared the precision of our width determination.
The findings of growth dependence in larval mortality have great implications for the interpretations of the early life history and the adult stages, since the growth rate of fish larvae can vary considerably between areas and seasons. Campana (1996) suggested that if survival were favoured by fast growth, the recruitment would be high in years with high mean growth rate during the larvae/juvenile stages. He found a good correlation between the average otolith size at settlement and year class strength of the cod from Georges Bank. Our results indicate, however, that large (otolith) sizes at settlement can be introduced by selective processes operating long before settlement. Hence, the entire larval/juvenile period would have to be considered if the previous growth history should be used as indicator of the survival and recruitment of a given year class.

Acknowledgements. We gratefully acknowledge the crew on RV 'Dana' and the technicians assisting with processing of samples in the laboratory of Danish Institute for Fishery Research, Department of Marine Ecology and Aquaculture. The study is a part of the EU-supported LIFECO-programme (Q5RS-2000-30183).

\section{LITERATURE CITED}

Anderson CS (1995) Calculating size-dependent relative survival from samples taken before and after selection. In: Dean J, Campana SE (eds) Recent development in fish otolith research. University of South Carolina Press, Columbia, p 455-465

Anderson JT (1988) A review of size dependent survival during pre-recruit stages of fishes in relation to recruitment. J Northw Atlant Fish Sci 8:55-66

Bailey KM, Houde ED (1989) Predation on eggs and larvae of marine fishes and the recruitment problems. Adv Marine Biol 25:1-83

Bolz GR, Lough RG (1988) Growth through the firstsix months of Atlantic cod Gadus morhua, and haddock Melanogrammus aeglefinus, based on daily otolith increments. Fish Bull US 86:223-235

Butler JL (1992) Collection and preservation of material for otolith analysis. In: Stevenson DK, Campana SE (eds) Otolith microstructure examination and analysis. Can Spec Publ Fish Aquat Sci 117:13-17

Campana SE (1990) How reliable are growth back-calculations based on otolith? Can J Fish Aquat Sci 47:2219-2227

Campana SE (1996) Year-class strength and growth rate in young Atlantic cod Gadus morhua. Mar Ecol Prog Ser 135: $21-26$

Campana SE (2001) Accuracy, precision and quality control in age determination, including a review of the use and abuse of age validation methods. J Fish Biol 59:197-242

Campana SE, Jones CM (1992) Analysis of otolith microstructure data. In: Stevenson DK, Campana SE (eds) Otolith microstructure examination and analysis. Can Spec Publ Fish Aquat Sci 117:73-100

Chambers RC, Miller TJ (1995) Evaluating fish growth by means of otolith increment analysis: special properties of individual level longitudinal data. In: Dean J, Campana SE (eds) Recent development in fish otolith research. University of South Carolina Press, Columbia, p 155-175 
Chick JH, Van Den Avyle MJ (2000) Effects of feeding ration on larval swimming speed and responsiveness to predator attacks: implications for cohort survival. Can J Fish Aquat Sci 57:106-115

Clemmesen C, Doan T (1996) Does otolith structure reflect the nutritional condition of a fish larvae? comparison of otolith structure and biochemical index (RNA/DNA ratio) determined on cod larvae. Mar Ecol Prog Ser 138:33-39

Cowan JH., Houde ED, Rose KA (1996) Size-dependent vulnerability of marine fish larvae to predation: an individualbased numerical experiment. ICES J Mar Sci 53:23-37

Cowan JH, Rose KA, Houde ED (1997) Size-based foraging success and vulnerability to predation: selection of survivors in individual-based model of larval fish populations. In: Chambers RC, Trippel EA (eds) Early life history and recruitment in fish populations. Chapman \& Hall, London, p 357-386

Cushing DH (1990) Plankton production and year-class strength in fish populations: an update of the match/mismatch hypothesis. Adv Mar Biol 26:249-293

Dower JF, Pepin P, Leggett WC (1998) Enhanced gut fullness and an apparent shift in selectivity by radiated shanny (Ulvaria subbifurcata) larvae in response to increased turbulence. Can J Fish Aquat Sci 55:128-142

Folkvord A, Hunter JR (1986) Size specific vulnerability of northern anchovy, Engraulis mordax, larvae to predation by fishes. Fish Bull US 84:859-569

Folkvord A, Rukan K, Johannessen A, Moskness E (1997) Early life history of herring larvae in contrasting feeding environments determined by otolith microstructure analysis. J Fish Biol 51:250-263

Francis RICC (1990) Back-calculation of fish length: a critical review. J Fish Biol 36:883-902

Geffen AJ (1995) Growth and otolith microstructure of cod (Gadus morhua) larvae. J Plankton Res 17:783-800

Hare JA, Cowen RK (1995) Effect of age, growth rate, and ontogeny on the otolith size -fish size relationship in bluefish, Pomatomus saltatrix, and the implication for backcalculation of size in fish early life history stages. Can J Fish Aquat Sci 52:1909-1922

Heath M, Gallego A (1997) From the biology of the individual to the dynamics of the population: bridging the gab in fish early life studies. J Fish Biol 51 (Suppl A):1-29

Houde ED (1987) Fish early life dynamics and recruitment variability. Am Fish Soc Symp 2:17-29

Hovenkamp F (1992) Growth-dependent mortality of larvae plaice Pleuronectes platessa in the North Sea. Mar Ecol Prog Ser 82:95-101

Hunter JR (1972) Swimming and feeding behaviour of larval anchovy Engraulis mordax. Fish Bull US 70:821-838

Leggett WC, Deblois E (1994) Recruitment in marine fishes: Is it regulated by starvation and predation in egg and larvae stages? Neth J Sea Res 32:119-134

Litvak MK, Leggett WC (1992) Age and size-selective predation on larval fishes the bigger-is-better hypothesis revisited. Mar Ecol Prog Ser 81:13-24

Luecke C, Rice JA, Crowder LB, Yeo SE, Binkowski FP (1990) Recruitment mechanisms of bloater in Lake Michigan: an analysis of the predatory gauntlet. Can J Fish Aquat Sci 47:524-532

Meekan MG, Fortier L (1996) Selection for fast growth during the larval life of Atlantic cod Gadus morhua on the Scotian Shelf. Mar Ecol Prog Ser 137:25-37

Miller TJ, Crowder LB, Rice JA, Marshall EA (1988) Larval size and recruitment mechanisms in fishes: toward a conceptual framework. Can J Fish Aquat Sci 45:1657-1670
Mosegaard H, Svedäng H, Taberman K (1988) Uncoupling of somatic and otolith growth rate in arctic chare (Salvelinus alpinus) as an effect of differences in temperature responses. Can J Fish Aquat Sci 45:1514-1524

Munk P (1993a) Differential growth of larval sprat Sprattus sprattus across a tidal front in the eastern North Sea. Mar Ecol Prog Ser 99:17-27

Munk P (1993b) Describing the distribution and abundance of small 0-group cod using a ring-net sampling and echointegration. ICES Council Meeting Paper GM-1993/G:40, ICES, Copenhagen, Denmark

Munk P (2002) Larval sand lance (Ammodytes sp.) in the diet of small juvenile wolffish (Anarhichas spp.): predation interactions in frontal water masses of western Greenland. Can J Fish Aquat Sci 59:1756-1767

Otterlei E, Folkvord A, Nyhammer G (2002) Temperature dependent otolith growth of larval and early juvenile Atlantic cod (Gadus morhua). ICES J Mar Sci 59:401-410

Pannella G (1971) Fish otolith: daily growth layers and periodical patterns. Science 173:1124-1127

Paradis AR, Pépin M, Pepin P (1999) Disentangling the effects of size-dependent encounter and susceptibility to predation whit an individual-based model for fish larvae. Can J Fish Aquat Sci 56:1562-1575

Pepin P (1991) Effect of temperature and size on development, mortality, and survival rate of the pelagic early life history stage of marine fish. Can J Fish Aquat Sci 48: 503-518

Pepin P, Shears TH, de Lafontaine Y (1992) Significance of body size to the interaction between a larvae fish (Mallotus villosus) and a vertebrate predator (Gasterosteus aculeatus). Mar Ecol Prog Ser 81:1-12

Pepin P, Dower JF, Benoít HP (2001) The role of measurement error on the interpretation of otolith increment width in the study of growth in larval fish. Can J Fish Aquat Sci 58(11):2204-2212

Pitchford JW, Brindley J (2001) Prey patchiness, predator survival and fish recruitment. Bull Math Biol 63:527-546

Puvanendran V, Brown JA (1999) Foraging, growth and survival of Atlantic cod reared in different prey concentrations. Aquaculture 175:77-92

Rice JA, Miller TJ, Rose KA, Crowder LB, Marshall EA, Trebis AS, Deangleis LD (1993) Growth rate variation and larval survival: inferences from an individual-based sizedependent predation model. Can J Fish Aquat Sci 50: 133-142

Sirois P, Dodson JJ (2000) Critical periods and growth-dependent survival of larvae of an estuarine fish, the rainbow smelt Osmerus mordax. Mar Ecol Prog Ser 203:233-245

Suthers I (1996) A guide to the extraction and interpretation of otholiths from larval and pelagic juvenile ArctoNorwegian Cod (Gadus morhua). Fisken Havet 13:1-13

Suthers I, Frank KT, Campana SE (1989) Spatial comparison of recent growth in post larval Atlantic cod (Gadus morhua) off south-western Nova Scotia: interior growth in a presumed nursery area. Can J Fish Aquat Sci 46: 113-124

West CJ, Larkin PA (1987) Evidence for size-selective mortality of juvenile sockeye salmon (Onocorhynchus nerka) in Babine Lake, British Columbia. Can J Fish Aquat Sci 44: 712-721

Williams PJ, Brown JA, Gotceitas V, Pepin P (1996) Developmental changes in escape response performance offive species of marine larval fish. Can J Fish Aquat Sci 53: $1246-1253$

Submitted: October 14, 2003; Accepted: June 8, 2004

Proofs received from author(s): August 19, 2004 